\title{
HOW TO INCREASE CIRCULARITY IN THE SWISS ECONOMY?
}

\author{
Cecilia Matasci *, Marcel Gauch and Heinz Böni
}

Empa, Swiss Federal Laboratories for Materials Science and Technology, Technology and Society Laboratory - Lerchenfeldstrasse 5, $\mathrm{CH}-9014$ St. Gallen, Switzerland

Article Info:
Received:
3 July 2020
Revised:
15 October 2020
Accepted:
25 November 2020
Available online:
26 February 2021
Keywords:
Circular economy
Life cycle assessment
Material flow analysis
Climate change
Domestic material consumption
WEEE

Article Info:

Revised:

15 October 2020

Accepted:

Keywords:

Circular economy

eycle assessmen

Climate chang

WEEE

\begin{abstract}
Environmental threats are triggered by the overconsumption of raw materials. It is therefore necessary to move towards a society that both reduces extraction and keeps the majority of the extracted raw materials in the socio-economic system. Circular economy is a key strategy to reach these goals. To implement it effectively, it is necessary to understand and monitor material flows and to define hotspots, i.e. materials that need to be tackled with the highest priority. This paper is aimed at determining how to increase circularity in the Swiss economy by means of a Material Flow Analysis coupled with a simplified Life Cycle Assessment. After having characterized material flows, we analyzed two types of hotspots: i) Raw materials consumed and/or disposed at high level, and ii) Raw materials whose extraction and production generates high environmental impacts. The Material Flow Analysis shows that each year $119 \mathrm{Mt}$ of raw materials enter the Swiss economy. Therefrom, $15 \mathrm{Mt}$ are derived from recycled waste inside the country; $67 \mathrm{Mt}$ leave the system yearly; 27 Mt towards disposal. Out of the disposed materials, $56 \%$ are recycled and re-enter the socio-economic system as secondary materials. Looking at hotspots; concrete, asphalt, gravel and sand are among materials that are consumed and disposed at high level. Yet, looking at greenhouse gas emissions generated during extraction and production, metals - including the ones in electrical and electronic equipment - as well as textiles are among the categories that carry the biggest burden on the environment per unit of material.
\end{abstract}

\section{INTRODUCTION}

The publication of the Planetary Boundaries concept in 2009 (Rockström et al., 2009) and its update in 2015 (Steffen et al., 2015) showed that global-scale alteration of biogeochemical flows, biosphere integrity, land-system change and climate change are the major environmental threats that humanity is facing nowadays. These threats are a consequence of human overconsumption of natural resources (O'Neill et al. 2018). It is therefore essential to understand factors that drive raw material consumption and the flows of materials that this generates. This allows tackling hotspots and developing pathways to reach a 'safe operating space for humanity' (Heijungs et al., 2014; O'Neill et al. 2018), for example by reducing extraction and keeping the majority of the extracted raw materials in the socio-economic system.

Broken down the Swiss economy, we see a need for quantifying flows of materials and energy with their related environmental impacts. Studies exist assessing the material input and the environmental consequences (Jungbluth et al., 2011; Frischknecht et al., 2014; Frischknecht et al., 2018), or the environmental consequences of resource and energy recovery in waste management systems (Haupt, 2018). However, to our knowledge there are no studies focusing on the material inputs and outputs of the entire economic system, including considerations about the recycling efficiencies and losses (incineration, landfilling).

This paper aims at determining how to increase circularity of raw materials in the Swiss economy. It does so by: i) Characterizing mass flows, ii) Assessing the environmental impacts generated by these flows, and iii) Defining which raw materials are hotspots, i.e. are either consumed and/or disposed at high level or their extraction and production generates high environmental impacts. The result of this research is meant to support the Swiss government in taking decisions for moving towards more circularity in material management.

\section{MATERIALS AND METHODS}

\subsection{Material flows of Swiss economy}

To address the circularity of the Swiss economy and to answer the research question of this paper, we carried out a static Material Flow Analysis (MFA) covering the material metabolism within the Swiss economy and coupled it 
with a Life Cycle Assessment (LCA). Material Flow Analysis (Baccini \& Brunner, 2012) helps to assess the material input into a national economy, its accumulation within the system and its output to other economies or to the environment (OECD, 2008). This research is based on the methodology developed in three sectoral studies. In each of them, a particular area of the Swiss economy was analyzed: construction (Gauch et al., 2016), mobility (Gauch et al., 2017), and production \& consumption (Matasci et al., 2018). For construction and mobility, we used a stock-driven approach. For the remaining production and consumption area, we applied an inflow-driven approach due to the lack of information on the existing stock and the impossibility to perform a bottom-up estimate. The reference year is 2018. Calculations were done using Microsoft Excel 2016.

Official statistics on masses of imported, domestically extracted and exported goods served as a basis for the calculation. In this research, we considered about 750 classes of goods registered, covering the entire Swiss economy, as for example industrial buildings, private cars, airplanes, stoves, pullovers, computers, or medicaments. For each of them, we determined the raw material composition and service lifetime. Additionally, we grouped them into 28 consumption categories (Table 1).

We examined 195 types of raw materials (e.g., reinforced concrete, sawn softwood, low-alloyed steel, wrought alloy aluminum, crude oil, cotton fiber, or polyethylene). We grouped them into 18 categories, as presented in Table 2. Materials in electric and electronic equipment as well as in batteries were aggregated in a distinct category called 'Electronics, batteries' to be able to look at them specifically.

Water and gold were not included in the frame of this study. Water was excluded due to the enormous quantities consumed (630 Mt/a) generating nonetheless relatively small environmental impacts $\left(0.1 \mathrm{Mt} \mathrm{CO}_{2}\right.$-eq./a, less than $1 \%$ of the total). Gold was disregarded for the opposite reason: the small quantities consumed (about $800 \mathrm{Mt}$ in 2018) generating massive environmental impacts (12 Mt $\mathrm{CO}_{2}$-eq., which is about $15 \%$ of the $\mathrm{GHG}$ emissions created

TABLE 1: Twenty-eight consumption categories covering the entire Swiss economy, classified by areas and sub-areas of the socio-economic system.

\begin{tabular}{|c|c|c|c|}
\hline Areas of the socio-economic system & Sub-areas & Consumption categories & Number of classes of goods \\
\hline \multirow[t]{9}{*}{ Construction } & \multirow[t]{6}{*}{ Buildings } & Single-family houses & 1 \\
\hline & & Apartment buildings & 1 \\
\hline & & Service buildings & 1 \\
\hline & & Industrial buildings & 1 \\
\hline & & Agricultural buildings & 1 \\
\hline & & Other buildings & 1 \\
\hline & \multirow[t]{3}{*}{ Civil engineering } & Streets & 1 \\
\hline & & Rail & 1 \\
\hline & & Infrastructure for supply and disposal & 1 \\
\hline \multirow[t]{12}{*}{ Mobility } & \multirow[t]{12}{*}{ Mobility } & Two wheels & 6 \\
\hline & & Passenger cars & 6 \\
\hline & & Transporters & 10 \\
\hline & & Lorries & 6 \\
\hline & & Buses & 4 \\
\hline & & Agricultural and industrial vehicles & 20 \\
\hline & & Trailers & 3 \\
\hline & & Trams & 1 \\
\hline & & Trains & 7 \\
\hline & & Boats & 4 \\
\hline & & Airplanes & 7 \\
\hline & & Cable cars & 3 \\
\hline \multirow[t]{7}{*}{ Production \& consumption } & Food & Food & 36 \\
\hline & \multirow[t]{5}{*}{ Living, working } & Furniture & 187 \\
\hline & & Clothing, accessories & 19 \\
\hline & & Communication, education & 24 \\
\hline & & Leisure, entertainment & 28 \\
\hline & & Health & 8 \\
\hline & Industry & Industry & 361 \\
\hline
\end{tabular}


TABLE 2: Eighteen categories of raw materials, classified by type. Electricity is expressed in tons of oil equivalents (toe) as described in Gauch et al. (2017)

\begin{tabular}{|c|c|c|}
\hline Type & $\begin{array}{l}\text { Categories of raw } \\
\text { materials }\end{array}$ & $\begin{array}{l}\text { Number of classes of } \\
\text { materials }\end{array}$ \\
\hline \multirow[t]{3}{*}{ Energy carriers } & Electricity (toe) & 2 \\
\hline & Motor fuel & 5 \\
\hline & Combustible & 3 \\
\hline \multirow[t]{2}{*}{ Food products } & Food & 38 \\
\hline & Fodder, animals & 23 \\
\hline \multirow[t]{13}{*}{ Solid materials } & Gravel, sand & 5 \\
\hline & Asphalt & 2 \\
\hline & Concrete & 4 \\
\hline & Brick & 6 \\
\hline & Glass, ceramics & 10 \\
\hline & Steel & 3 \\
\hline & Aluminum & 4 \\
\hline & Other metals & 24 \\
\hline & Plastics & 14 \\
\hline & Textiles & 6 \\
\hline & Wood, paper & 11 \\
\hline & Electronics, batteries & 10 \\
\hline & Chemicals & 25 \\
\hline
\end{tabular}

by all other materials consumed annually in the country put together). An analysis of the material flows and the environmental impacts produced by the consumption of these two materials can be found in Matasci et al. (2018). Finally, for each category of raw materials, we defined a disposal pathway.

\subsection{Environmental impacts generated by mass flows}

Based on the determination of quantities and compositions of the flows we calculated a simplified Life Cycle Assessment (LCA). LCA is a method developed to assess environmental impacts associated with the different life stages of a product or a process, from cradle to grave. As functional unit, we considered a ton of used raw material. We employed the Life Cycle Inventory database ecoinvent v. 3.2-3.5 (ecoinvent 2016, 2018). This was combined with the results of the MFA to assess the environmental impacts in terms of greenhouse gas (GHG) emissions and total environmental impact of the different mass flows. The calculation of the total environmental impact is based on the Ecological Scarcity Method (Frischknecht \& Büsser Knöpfel 2013), developed specifically for Switzerland. This method allows measuring the current distance to politically determined targets on the broadest possible basis.

System boundaries for raw material flows were set on the level of the political borders of Switzerland. Environmental impacts are however not limited by these borders and can take place inside and/or outside the country. Consequently, the GHG emissions and other environmental impacts hidden behind imported products are also taken into account.
We considered both primary and secondary materials. Primary raw materials are 'virgin materials, natural inorganic or organic substances, such as metallic ores, industrial minerals, construction materials or energy fuels, used for the first time' (EU 2017). Secondary raw materials are raw materials derived from recycling of waste that can be used in manufacturing a new product. Imported raw materials can be a combination of both.

\section{RESULTS AND DISCUSSION}

According to the results of the MFA, about $119 \mathrm{Mt}$ of raw material flew into the Swiss economy in 2018. Of these, $104 \mathrm{Mt} / \mathrm{a}$ came from either domestic extractions or imports. The remaining $15 \mathrm{Mt}$ (13\%) re-entered the system annually as secondary raw materials either for the same purpose (recycling) or for a different one (downcycling, upcycling). From the $119 \mathrm{Mt} / \mathrm{a}, 52 \mathrm{Mt} / \mathrm{a}$ stayed in the stock, mainly concrete, sand and gravel in construction. The remaining $67 \mathrm{Mt} / \mathrm{a}$ exited the Swiss economy. Thereof; 22 Mt/a were dissipated into the environment, for example in form of burned fuel for mobility and combustible, consumed food or dispersed chemicals (e.g. pesticides). On top of that, $18 \mathrm{Mt} / \mathrm{a}$ were exported and $27 \mathrm{Mt} / \mathrm{a}$ were disposed (Figure 1). Of the disposed materials, $18 \mathrm{Mt} / \mathrm{a}(67 \%)$ were either recycled or composted (Figure 2). We consider composted materials to go into the environment (either into the ground or into air) and are therefore not part of the flow of secondary materials reentering the system (Figures 1, 2).

The disposal phase is composed of various intermediate stages. These include cross-exchanges of solid materials between disposal processes (Figure 2). Examples are residues from incineration plants (slag), which are returned to the recycling process, or residues from waste water treatment plants (sewage sludge), which are incinerated. Figure 2 shows some of the modelled flows in more details. To note that a share of the substances entering the disposal process 'disappears' from the mass balance, for example by being converted into gaseous substances in incineration or composting/biogas plants.

Figure 3 shows both masses and environmental impacts for the 18 categories of raw materials in more details. On the left-hand side of the figure, information on the mass entering the disposal path is depicted for each category of raw materials, split in the different fates these are facing (recycling, incineration, landfill, compost and biogas). Masses consumed are shown for comparison by a broken line. Statistical data corroborate these results where information is available (FOEN, 2019). In the center of Figure 3, the GHG generated by disposal and consumption are illustrated. The figure shows how emissions produced by disposal are much smaller than the ones created by extraction, production and consumption of these raw materials (broken line in the figure). It is however important to note that these results are connected with a certain level of uncertainty, as specific values for the end of life of many raw materials are lacking in the ecoinvent database. On the right-hand side of Figure 3, the GHG emissions generated by the production and transport to the consumer of a mass 


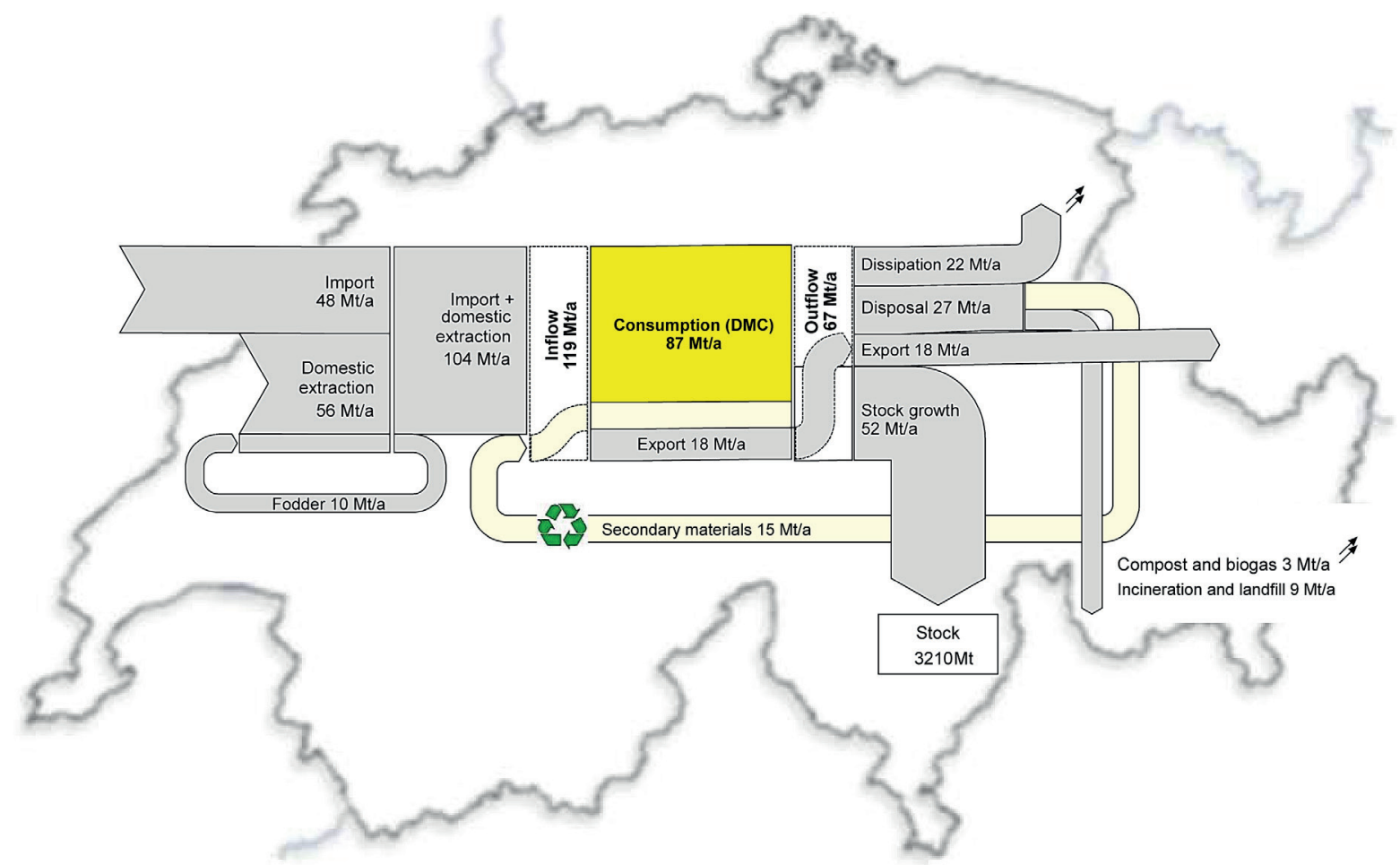

FIGURE 1: Aggregated mass flow for Switzerland in 2018. In yellow the Domestic Material Consumption (DMC), in light yellow the flow of secondary materials reentering the system (Matasci et al., in preparation). Composted materials are considered to go directly into the environment (in the ground / into air) and are not part of the flow of secondary materials reentering the system.

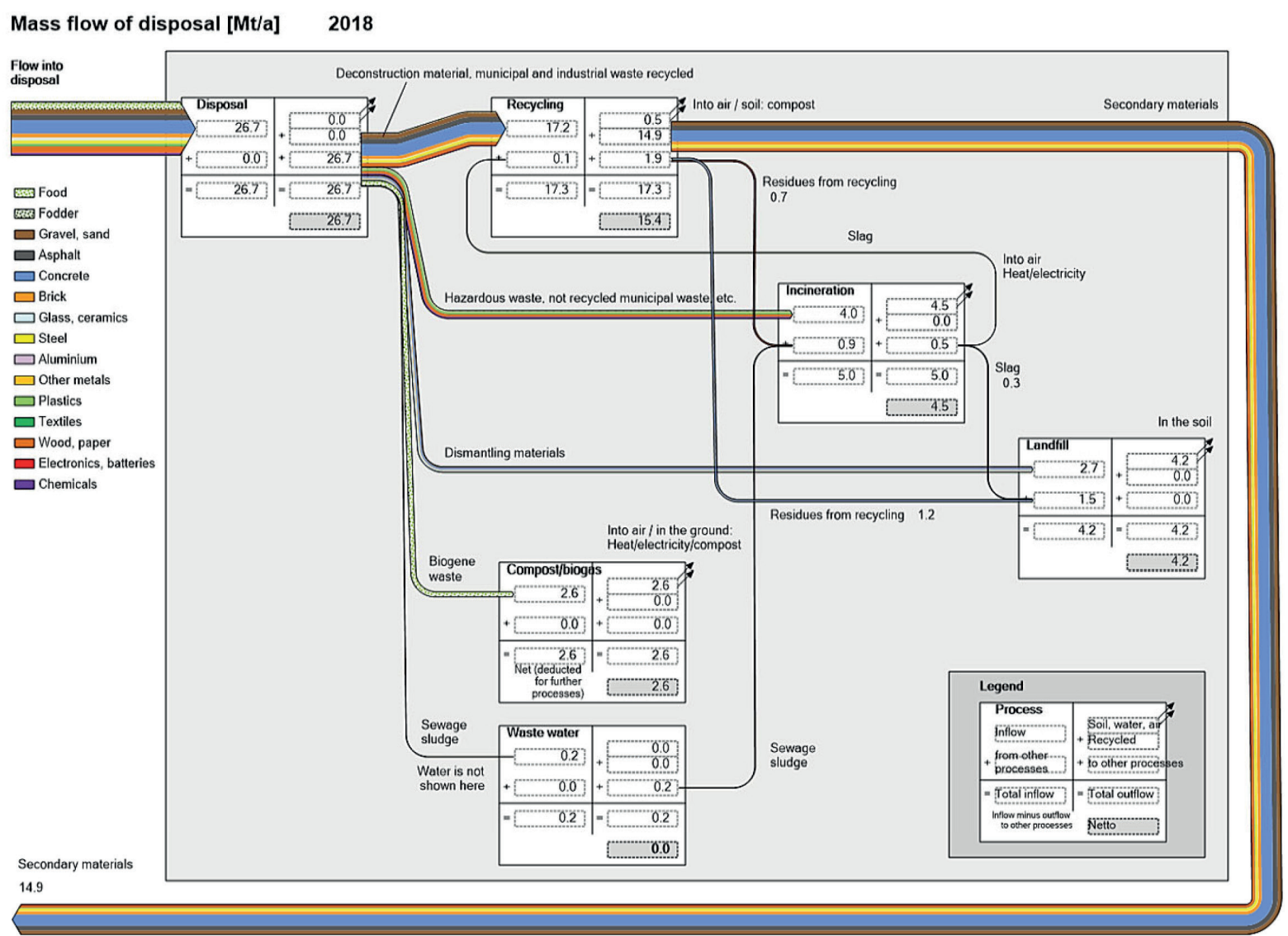

FIGURE 2: Disposal mass flows. The width of the arrows shows the relative mass of raw materials being disposed annually. Some of the raw materials are dissipated into the environment. These are marked with a double arrow. 
unit of primary vs. a mass unit of secondary raw material are shown.

Figures 2 and 3 illustrate that the majority of the disposed raw materials are inert materials coming from the construction sector (concrete, sand and gravel, asphalt, brick). As Switzerland decided to stop landfilling of organic waste back in 2000 (FOEN, 1999), organic waste is nowadays either composted, incinerated or recycled.

Many raw materials re-enter the system as secondary raw materials. Among them, concrete is mainly downcycled in civil engineering structures. Recycled concrete in the building sector is only slowly gaining acceptance in Switzerland. Food is also eliminated in high quantities. The $2.9 \mathrm{Mt} / \mathrm{a}$ of disposed food (about $1 / 3$ of the food entering the system) is food waste generated either by consumers or within the supply chain (Beretta \& Hellweg, 2019). Fuel for mobility and combustible consumed are dissipated into the environment during combustion and therefore do not appear in the disposal path.

An additional result established by this study and depicted in Figure 3 is the recognition that big masses of disposed materials do not necessarily carry the highest environmental burden. The disposal of concrete for example generates a relatively small amount of GHG emissions in absolute terms, whereas the disposal of chemicals and plastics creates far higher emissions even if the discarded masses are smaller. This is also true for consumption: the raw materials depleted in higher amount are not the ones that generate the highest burden for the environment during their extraction, transport and consumption. The life phases of concrete up to consumption for example produce a far smaller amount of GHG per unit of material as the ones of electronics and batteries, metals, or textiles.

Another aspect shown on the right hand-side of Figure 3 is that the production of secondary raw materials develops much lower emissions than the one of primary raw materials. This highlights the importance of moving from the current linear economy towards a circular economy. This is particularly true for metals in waste electrical and electronic equipment, WEEE) which are often critical. Critical raw materials are raw materials of a high importance to the economy and whose supply is associated with a high risk (EU 2017). Examples are indium and neodymium contained respectively in flat screens and in magnets. The recycling of these metals is not yet established in Switzerland (Böni et al. 2015). If the totality of electronics and batteries category (WEEE) would be recycled and used for the same purpose, emissions generated by Swiss consumption could decrease of about $3 \mathrm{t} \mathrm{CO}_{2}$-eq./a. On the other hand, some materials disposed contain pollutants that should not return into the system as for example brominated flame-retardants (BFR) in plastics (Haarman et al. 2018). Recycling is therefore not always possible or not the best option.

This study presents three main methodological limitations. The first one concerns the different approaches used for the various sectors of the economy, namely a stock-driven approach for the building and the mobility sectors and an inflow-driven method for the remaining sectors of the economy. In future research, a common methodology should be used instead. The second limitation

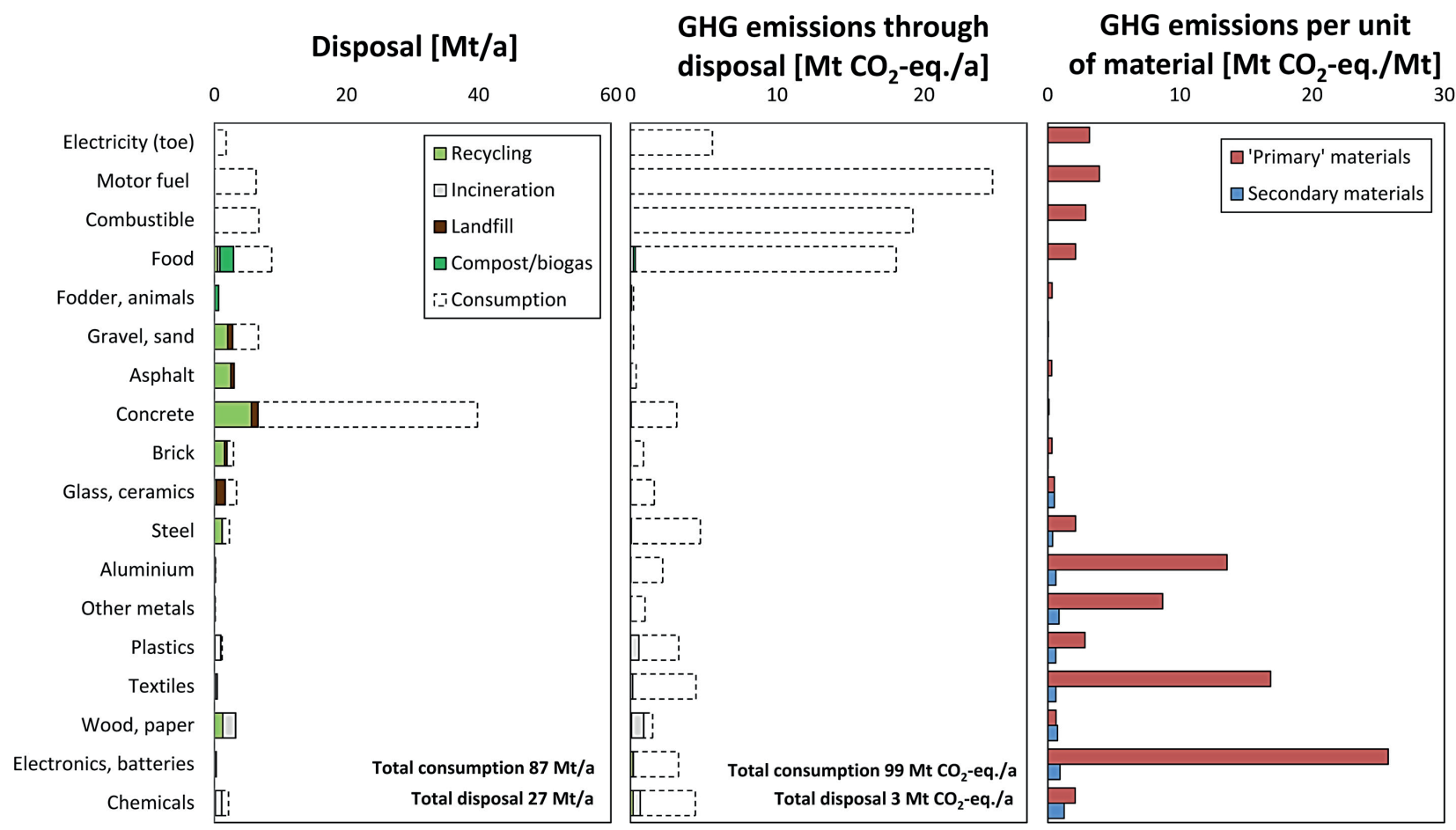

FIGURE 3: From left to right: i) Annual masses of disposed raw materials, differentiated by their disposal fate (recycling, incineration, landfill, compost/biogas). ii) GHG emissions created during the disposal of these raw materials. In i) and ii) the mass of annually consumed raw materials respectively the GHG emission developed are also shown for comparison (broken line). iii) GHG emissions generated by production and transport per unit of consumed material for both primary and secondary raw materials. What is illustrated here as 'primary' material can also contain secondary materials if imported, for example metal scraps. 
concerns the limited information on the average material composition of the different categories of goods analyzed. Data came from different sources and do vary in quality. When data was not available, best guess assumptions of the authors were necessary. Finally, it was not possible to find an equivalent in the ecoinvent database for all raw materials embedded in the approx. 750 categories of goods. Sometimes proxies had to be selected instead, in particular for chemicals.

\section{CONCLUSIONS}

This study highlights the necessity to increase circularity for most categories of raw materials due to three reasons: i) the large masses being consumed and disposed, ii) the high environmental impacts generated either ii) during the lifespan and/or iii) by primary production in relation to the recovery of secondary materials.

The disposed amount and the environmental impact caused can vary largely depending on the type of raw material considered. Material hotspots identified due to the large mass eliminated yearly in Switzerland are concrete, asphalt, gravel and sand. For concrete, even if the environmental impacts generated by its disposal are relatively small, there are other aspects to be examined. These are for example the finite nature of its main component, gravel and the potential conflict with other land uses; the amount of energy required to produce its binder, cement; as well as conflicts in land use through the disposal of waste concrete and for the extraction of gravel (FSKB, 2017). Nowadays, concrete from demolition activities in Switzerland is mainly downcycled. The use of recycled concrete in the construction sector consequently needs to be further promoted.

Concerning environmental impacts created through the disposal of materials; hotspots identified are plastics, chemicals and food. The avoidance of food waste and the recycling of plastics could therefore be two pertinent measures to reduce the actual environmental burden of the Swiss waste management system. It is worth noting that the environmental impacts caused by the consumption of materials are generally much higher than the ones generated during the disposal phase. Hence, more effort should also be put into limiting consumption in the first place and into keeping raw materials in the system. This can be done for example by expanding the lifespan of goods or by reusing them.

In addition, for many raw materials the primary production has a higher environmental impact in comparison to their secondary production. This is particularly the case for metals, including those embedded in electrical and electronic equipment. For some metals as aluminum in beverage cans or tinplate in tin cans, the recycling rate is already rather high (Haupt, 2018). However, for some others, as for example critical metals like indium and neodymium in electronic waste, the actual recycling rate in Switzerland is close to zero (Böni et al., 2015) and therefore should be further improved.

An additional outcome of this study is the recognition that there is a need for a better monitoring of some flows.
Our results show that not all flows related to disposal are covered by official statistics or that data collected for some of them are approximate. This is the case, for example, for waste flows generated by industry or for the composition of waste produced by households. The last one is only investigated in-depth every 10 years (FOEN, 2014).

Finally, this study shows that circularity cannot be applied to all raw materials entering a socio-economic system. In fact, some raw materials are dissipated into the environment when consumed, as for example motor fuel, combustible, food or some chemicals. Circularity alone can therefore not bring us to a more sustainable society. Other measures as the phasing-out of fossil fuels are also needed.

\section{ACKNOWLEDGEMENTS}

This paper has been written as part of the MatCH Project 'Material and Energy Resources and their Environmental Impacts in Switzerland', funded by the Swiss Federal Office for the Environment FOEN. We would like to thank Dr. Bernhard Hammer and Dr. Michel Monteil (FOEN) as well as Michael Gasser and Andreas Bill (both Empa) for the specific thoughts and comments provided.

\section{REFERENCES}

Baccini, P., Brunner, P., 2012. Metabolism of the Anthroposphere: Analysis, Evaluation, Design (2nd Edition).

Beretta, C., Hellweg, S., 2019. Lebensmittelverluste in der Schweiz: Umweltbelastung und Vermeidungspotenzial. ETH Zürich, commissioned by the Swiss Federal Office for the Environment FOEN.

Böni, H., Wäger, P., Thiébaud, E., Du, X., Figi, R., Nagel, O., Bunge, R., Stäubli, A., Spörry, A., Wolfensberger-Malo, M., et al., 2015. Rückgewinnung von kritischen Metallen aus Elektronikschrott am Beispiel von Indium und Neodym. Projekt e-Recmet. Schlussbericht; sine nomine.

Ecoinvent, 2018. ecoinvent database v.3.5 (Status August 2018).

Ecoinvent, 2016. ecoinvent database v.3.2 (Status January 2016).

EU, 2017. Study on the review of the list of Critical Raw Materials Criticality Assessments. Final report. European Union EU.

FOEN, 2019. Abfallmengen und Recycling 2018 im Überblick. Swiss Federal Office for the Environment FOEN.

FOEN, 2014. Erhebung der Kehrichtzusammensetzung 2012. Swiss Federal Office for the Environment FOEN.

FOEN, 1999. Keine brennbaren Abfälle mehr auf Deponien nach dem 1. Januar 2000. Swiss Federal Office for the Environment FOEN. https://www.admin.ch/gov/de/start/dokumentation/medienmitteilungen.msg-id-2855.html

Frischknecht, R., Nathan, C., Büsser Knöpfel, S., Itten, R., Wyss, F., Hellmüller, P., 2014. Entwicklung der weltweiten Umweltauswirkungen der Schweiz - Umweltbelastung von Konsum und Produktion von 1996 bis 2011.

Frischknecht, R., Nathani, C., Alig, M., Stolz, P., Tschümperlin, L., Hellmüller, P., 2018. Umwelt-Fussabdrücke des Schweizer Konsums Zeitlicher Verlauf 1996 bis 2015.

Frischknecht, R., Büsser Knöpfel, S., 2013. Swiss Eco-Factors 2013 According to the Ecological Scarcity Method. Swiss Federal Office for the Environment FOEN.

FSKB, 2017. Info - Informationsmagazin des FSKB Fachverband der Schweizerischen Kies- und Betonindustrie. Fachverband der Schweizerischen Kies- und Betonindustrie FSKB.

Gauch, M., Matasci, C., Hincapié, I., Böni, H., 2017. Projekt MatCH - Mobilität: Material- und Energieressourcen sowie Umweltauswirkungen der Mobilität Schweiz. Empa, commissioned by the Swiss Federal Office for the Environment FOEN.

Gauch, M., Matasci, C., Hincapié, I., Hörler, R., Böni H., 2016. Projet MatCH - Bau: Material- und Energieressourcen sowie Umweltauswirkungen der baulichen Infrastruktur der Schweiz. Empa, commissioned by the Swiss Federal Office for the Environment FOEN. 
Haarman, A., Gasser, M., Böni, H., Rösslein, M., Wäger, P., 2018. Brominated Flame Retardants in Large Household Appliances. Empa.

Haupt, M., 2018. Environmental Assessment of Resource and Energy Recovery in Waste Management Systems. ETH Zurich.

Heijungs, R., de Koning, A. \& Guinée, J.B., 2014. Maximizing affluence within the planetary boundaries. Int J Life Cycle Assess 19, 13311335. https://doi.org/10.1007/s11367-014-0729-y.

Jungbluth, N., Stucki, M., Leuenberger, M., 2011. Environmental Impacts of Swiss Consumption and Production. Swiss Federal Office for the Environment FOEN.

Matasci, C., Gauch, M., Böni, H., in preparation. Projet MatCH - Synthese: Material- und Energieflüsse der schweizerischen Volkswirtschaft - Mit Bewertung der Umweltbelastungen. Empa, commissioned by the Swiss Federal Office for the Environment FOEN.
Matasci, C., Gauch, M., Böni, H., 2018. Projekt MatCH - Produktion\&Konsum: Material- und Energieressourcen von Produktion und Konsum in der Schweiz. Empa, commissioned by the Swiss Federal Office for the Environment FOEN.

OECD, 2008. Measuring Material Flows and Resource Productivity Synthesis Report. Organisation for Economic Co-operation and Development OECD.

O'Neill, D. W., Fanning, A.L., Lamb, W.F. et al., 2018. A good life for all within planetary boundaries. Nat Sustain 1, 88-95. https://doi. org/10.1038/s41893-018-0021-4

Rockström, J., Steffen, W., Noone, K., Persson, Å., Chapin, F. S., Lambin, E. F., Lenton, T. M., et al., 2009. A Safe Operating Space for Humanity. Nature 461 (7263): 472-75.

Steffen, W., Richardson, K., Rockström, J., Cornell, S. E., Fetzer, I., Bennett, E. M., Biggs, R., et al., 2015. Planetary Boundaries: Guiding Human Development on a Changing Planet. Science 347 (6223): 1259855. 